\title{
Деонимы с ономастическим компонентом в русскоязычном политическом медиадискурсе
}

\section{Deonyms with an Onomastic Component in the Russian Political Media Discourse}

\author{
Элена Томашкова \\ (Чешске-Будеёвице, Чехия)
}

\section{Абстракт:}

В статье рассматриваются новые лексические единицы с ономастическим компонентом в русскоязычном политическом медиадискурсе. Особое внимание уделяется новым продуктивным словообразовательным моделям. Так, в последние годы в русском языке СМИ широкое распространение получили слова с английским суффиксом -ing, образованные на базе имён собственных. Как правило, производящей основой таких лексем являются фамилии политических деятелей. Большинство деонимов этой группы обозначают «митинг в поддержку конкретного политика» или определённое действие, олицетворением которого является политическая персона. Также исследуются композиты, образованные по заимствованным из английского языка моделям. Широкое распространение деонимов в русском языке СМИ свидетельствует о тенденции к персонификации политики, склонности к языковой игре, стремлении к повышению экспрессивности публицистического текста.

\section{Ключевые слова:}

деоним; антропоним; политический медиадискурс; словообразовательная модель; неологизм

\section{Abstract:}

The paper explores new lexical units of the Russian political media discourse that have anthroponyms in their composition. Particular attention is paid to new productive word-building models. So, in recent years in the Russian media language words with 
the English suffix -ing, formed on the basis of their own names, has been widely spread. As a rule, the bases for such lexemes are the names of politicians. Most of the deonyms of this group have the semantics of «meeting in support of a specific politician» or a certain action personified by a political figure. Composites formed according to models borrowed from the English language are also explored. The wide dissemination of deonyms in the Russian media language testifies to the trend towards personification of politics, the propensity to language game, the desire to increase the expressiveness of the journalistic text.

\section{Key words:}

deonym; anthroponym; political media discourse; word-formation model; neologism

Русскоязычный сегмент политического медиадискурса, к которому относятся не только собственно российская медиасфера, но и СМИ всего постсоветского пространства, представляет собой динамично развивающуюся систему, которая параллельно с сохранением традиционных для русского языка словообразовательных моделей, впитывает новые, проникающие, в первую очередь, из английского языка. Влиянием английского объясняется, в том числе, и активное использование лексических единиц, образованных от имён политических деятелей. Новые тенденции в образовании деонимов с ономастическим компонентом и особенности их функционирования в русскоязычном политическом медиадискурсе нуждаются в теоретическом осмыслении, что и обуславливает актуальность данного исследования.

Язык русскоязычной медиасферы, в том числе в лингвокультурном и семантическом аспектах, комплексно изучается М.Горамом, И. Лунде и М. Паульсеном ${ }^{1}$. Лексические процессы в российском политическом дискурсе на материале онлайн-СМИ исследуются В. Беловым ${ }^{2}$. Анализ стиля и риторики политического медиадискурса и изучение воздействия на него новых технологий представлены в работе И. Лунде 3 .

Специфика оценочных номинаций политиков рассматривается в работах В. Катерминой, Е. Конечной, А. Якушевой ${ }^{4}$. Так, проведённое А. Якушевой иссле-

1 GORHAM, M. S., LUNDE, I., PAULSEN, M.: Digital Russia: The Language, Culture and Politics of New Media Communication. London: Routledge, 2014, $312 \mathrm{p}$.

2 BELOV, V.: Nekotoryje leksičeskije processy v rossijskom političeskom diskurse (na materiale rossijskich Internet-gazet). Zeitschrift für Slavische Philologie, 2016, vol. 72, iss. 2, pp. 383-411.

3 LUNDE, I.: Hashtag Poetics: Political humour on Russian Twitter. Zeitschrift für Slawistik, 2016, vol. 61, iss. 1, Special Issue: Contemporary Eastern European political discourse, pp. 102-118.

4 KATERMINA, V.V.: Ocenočnyje nominacii politikov (na materiale russkoj i anglijskoj substandartnoj leksiki). Političeskaja lingvistika, 2015, $\mathrm{nr}_{3}$ (53), s. 26-31; KONIECZNA, E.: Polish onomastic 
дование позволяет сделать вывод о том, что имена собственные приобретают сигнификативное и коннотативное значение и концептуализируются, т.е. имена приобретают свойство концепта. При этом выбор трансформационной модели обуславливается прагматическими замыслами автора-журналиста 5 .

Возможности и потенциал в русском языке инговых дериватов анализируются В. Григорьевым, А. Дьяковым и Е. Скворецкой 6 .

Использованию антропонимов посвящены работы В. Маркевич ${ }^{7}$ и Е. Гладченковой ${ }^{8}$. Базовым для настоящего исследования является тезис Е.Гладченковой о том, что, «становясь компонентом фразеологической единицы, имя собственное начинает выполнять функцию имени нарицательного, становится обобщенным наименованием однородных предметов, обладающих совокупностью определённых свойств (например, Иван Грозный - человек с сильным, волевым характером). Оним перестает быть выражением индивидуального, единичного предмета, но сохраняет генетическую и смысловую связь с исходным значением имени собственного» 9 .

Материалом для исследования стали тексты политической тематики русскоязычных интернет-СМИ постсоветского пространства. В процессе исследования использовался описательный метод для изучения функционирования лексем-деонимов и их характеристики, а также компонентный анализ для исследования семантики лексических единиц.

В процессе образования новых слов на базе имён известных лиц русский язык традиционно ограничивался формантами -изм, -ист и -щцина, соответственно семантика деонимов предполагала три основных варианта: «идеологическая

derivatives in the contemporary political discourse in the light of internationalization of Slavic languages. Zeitschrift für Slawistik, 2011, vol. 56, iss. 1, pp. 97-107; JAKUŠEVA, A. V. K semantike političeskogo teksta: antroponimy v funkcional'noj srede setevych sredstv massovoj informacii. Gumanitarnyje, social'no-èkonomičeskije i obščestvennyje nauki, 2014, nr 6, s. 1-6.

5 JAKUŠEVA, A. V.: K semantike političeskogo teksta: antroponimy v funkcional'noj srede setevych sredstv massovoj informacii. Gumanitarnyje, social'no-èkonomičeskije i obščestvennyje nauki, 2014, nr 6, s. 3.

6 GRIGOR'JEV, V.P.: Svetlojebuduščeje «ingovychform» v russkom poètičeskom jazyke. 2005.<http:// www.vavilon.ru/textonly/issue13/grigoriev.html>. [online]. [cit. 1. 12. 2019]; D’JAKOV, A. I., SKVORECKAJA, Je. V.: Suffiks -ing zavojevyvajet svoi pozicii v russkom slovoobrazovanii. Sibirskij filologičeskij žurnal, 2013, $\mathrm{nr}$ 4, s. 180-186.

7 MARKEVIČ, V. I.: Nacional'no-kul'turnaja specifika frazeologizmov s komponentom-antroponimom $v$ russkom, belorusskom i nemeckom jazykach. Filologičeskije nauki. Voprosy teorii i praktiki, 2014, nr 7 (37), II, s. 136-139.

8 GLADČENKOVA, Je. A.: Izmenenije vnešnej $i$ vnutrennej formy precedentnych antroponimov $v$ žargonnoj frazeologii. Izvestija Južnogo federal'nogo universiteta. Filologičeskije nauki, 2011, nr 3, s. 156-162.

9 Там же, s. 157. 
доктрина, политический курс», «сторонник доктрины», «общественно-политическое явление, характеризующиеся признаком, названным мотивирующим словом» (например, сталинизм, сталинист, сталинщина). Однако в настоящее время наблюдается интенсивное расширение арсенала деривационных моделей и семантических групп данного разряда лексики. Современные лингвистические исследования отмечают появление в русском языке (в первую очередь, в сегменте языка СМИ) лексических инноваций, созданных при помощи формантов или по словообразовательным моделям английского языка.

Одним из самых значительных по количеству созданных русских окказионализмов является пласт инговых дериватов. В. Григорьев образно называет этот процесс «инговым цунами» ${ }^{10}$. Отмечая, что в английском языке большая часть таких лексем образована от глаголов, исследователи указывают на то, что в русском языке налицо достаточно регулярный сдвиг в значении подобных слов на -инг, образованных на русской почве, по сравнению с английскими словами-прототипами, так как многие из них образованы от русских существительных, т. е. они как бы поручают иноязычному суффиксу обозначать процессуальную континуальность ${ }^{11}$.

В своё время В.Григорьев высказал гипотезу о высокой вероятности возникновения в русском языке инговых дериватов от имен известных людей ${ }^{12}$. По его мнению, область отношений суффикса -инг с полем личных имен содержит много подводных камней политического, правового и этического характера, однако едва ли больше, чем иные сферы словотворчества и живые оценки референтов и денотатов. Гипотеза В. Григорьева оказалась верной - и не только для русского, но и для других славянских языков, о чём свидетельствует, например, исследование морфологической и семантической структуры польских ономастических производных в публицистическом дискурсе, проведённое Е. Конечной. Польская исследовательница отмечает, что большинство подобных эпонимов создаётся при помощи иностранных аффиксов. Это говорит о прогрессирующей интернационализации славянских языков, всё больше полагающихся на неродные аффиксы и деривационные шаблоны. По мнению

10 GRIGOR'JEV, V.P.: Svetloje buduščeje «ingovych form»v russkom poètičeskom jazyke. 2005. <http:// www.vavilon.ru/textonly/issue13/grigoriev.html>. [online]. [cit. 1. 12. 2019].

11 D'JAKOV, A. I., SKVORECKAJA, Je. V.: Suffiks -ing zavojevyvajet svoi pozicii v russkom slovoobrazovanii. Sibirskij filologičeskij žurnal, 2013, $\mathrm{nr} 4$, s. 184.

12 GRIGOR'JEV, V.P.: Svetloje buduščeje «ingovych form»v russkom poètičeskom jazyke. 2005. <http:// www.vavilon.ru/textonly/issue13/grigoriev.html>. [online]. [cit. 1. 12. 2019]. 
учёной, такие лексические инновации являются средством публицистического выражения и оружием, используемым в политической борьбе $\mathrm{e}^{13}$.

Используемые в русскоязычном публицистическом дискурсе деонимы, образованные при помощи суффикса -инг на базе имён политиков, представлены двумя семантическими группами. Слова первой группы имеют значение «характерные действия, поведение определённого политического деятеля». Так, от фамилии Анатолия Чубайса, автора печально известной в России приватизации 9о-х годов прошлого века, образована лексема чубайсинг с семантикой «экономическое жульничество, обман», например: Толлинг - это замаскированныцй чубайсинг (Проза.ру, 2о. 9. 2017).

Одним из ярких и популярных в российской медиасфере деонимов данной группы является псакинг, обязанный своим возникновением специфической манере ведения брифингов экс-спикера Госдепа США Дженнифер Псаки. Дефиниция деонима приводится в статье журналиста Георгия Филимонова «Технология «псакинга». Что это?», посвящённой американской модели ведения информационной войны»: «Дженнифер Псаки, сама того не ведая, стала именем нарицательным - неформальным названием (в российской блогосфере) технологии «псакинга» - специфического способа подачи информации в её театрализовано-неуклюжей интерпретации» (Свободная пресса, 6. 6. 2016).

Лексема устойчиво закрепилась в русскоязычном медиадискурсе и продолжает активно использоваться, невзирая на то, что в 2015 году Дженнифер Псаки ушла с поста. Об этом свидетельствует регулярное употребление деонима в заголовках СМИ: Псакинг Don't stop (Ридус, 5. 6. 2014); Полный псакинг: вспоминаем самые яркие ляпы экс-представителя Госдепа (Вести FM, 26. 3. 2015); А какой у вас псакинг? (CBSMEDIA, 10. 7. 2017). Более того, когда на смену Дженнифер Псаки пришёл новый представитель Госдепа США Курт Волкер, его профессиональный стиль был охарактеризован при помощи той же лексемы: Лицензия на убийство. Курт Волкер включил Псакинг (Империя, 25. 7. 2017).

Вторая группа инговых деонимов имеет семантику «митинг в поддержку конкретного политика» и является на данный момент достаточно продуктивной. Первый неологизм такого рода, путинг, образованный от фамилии президента РФ, возник ещё в начале 2000-х годов. Точное авторство неологизма неизвестно, но уже вышедшая в 2003 году книга журналистки Елены Трегубовой «Байки кремлевского диггера» включала главу с названием «Легкий путинг». Деривационная модель, по которой построен неологизм, не совсем ясна. Это может быть аффиксация с компонентами Путин + -инг или сокращение Путин +

13 KONIECZNA, E.: Polish onomastic derivatives in the contemporary political discourse in the light of internationalization of Slavic languages. Zeitschrift für Slawistik, 2011, vol. 56, iss. 1, p. 97. 
митинг. Второй вариант представляется более вероятным. Однако, как бы то ни было, лексема (имеющая отрицательные коннотации) быстро приобрела широкую популярность в оппозиционных СМИ.

По аналогии с неологизмом путинг образуются другие лексемы. Активизация протестного движения в России после выборов в думу 2011 года создала условия для появления неолексемы навальнинг (от фамилии российского оппозиционера Алексея Навального) со значением «митинг против путинского режима». Неологизм употребляется преимущественно в текстах провластных медиа с отрицательной коннотацией: «Навальнинг» как ответ на «путинг»: кто согнал людей на митинг 18 июля? (Новый день, 26. 7. 2013), Александр Роджерс: Пара вилок в спину завтрашнему навальнингу (Журналистская Правда, 11. 6. 2017). Однако в последнее время наблюдается нейтрализация негативной семантики и переход слова в разряд общеупотребительных. Например, интернет-газета «Фонтанка» даёт материал с заголовком: Преподаватель ЛЭТИ о «навальнинге»: По сравнению с Северной Кореей Россия - образеи демократии (Фонтанка, 29. 3. 2017).

В 2016 году после выступлений сторонников главы Чечни Рамзана Кадырова появился неологизм кадыринг: \#Кадыринг (Радио Свобода, 22. 1. 2016), После кадыринга осталось много мусоринга: реакиия соисетей на митинг в Грозном (Гордон.uа, 23. 1. 2016).

Характерной особенностью инговых деонимов с семантикой «митинг в поддержку политика» является то, что возникают они в среде идейных противников определённого политика, но затем, получив широкое распространение, теряют негативные коннотации и начинают использоваться обоими политическими лагерями. Это позволяет предположить, что со временем модель «фамилия политика (как производящая основа) + суффикс -инг» в русском языке (во всяком случае, в языке СМИ) будет восприниматься как норма.

Под воздействием английских словообразовательных моделей в русском медиадискурсе появляются деонимы-композиты, в которых первая часть представляет собой имя собственное политика, а вторая - элемент его политической активности. Ярким примером в английском языке подобного композита является obamacare (реформа здравоохранения, проведённая экс-президентом США Бараком Обамой).

До настоящего времени подобные сложные слова не были характерны для русского языка. Однако в 2017 году в русскоязычном сегменте медиадискурса появился и начал активно использоваться неологизм Михо-Майдан со значением «акции протеста в Украине, организованные Михаилом Саакашвили». Необходимо отметить, что традиционная номинация явления 
(существительное + имя политика в родительном падеже - Майдан Михо) оказалась единичной: «Майдан Михо», или Саакашвили один на один с Порошенко (Украинская правда, 20. 10. 2017). Подавляющее большинство СМИ использовало именно композит. Иногда с дефисом: Михо-майдан: Саакашвили обвинил Кремль в поддержке Порошенко (ИА REGNUM, 18. 10. 2017), а иногда в слитной форме, но с написанием обеих частей слова с прописной буквы: МихоМайдан под Радой сняли с высоты птичьего полета (Страна.uа, 8. 10. 2017).

Разница в написании связана, как нам кажется, с тем, что для русского языка сложные слова с таким порядком расположения компонентов пока не являются привычными. Можно предположить, что в качестве нормы закрепится цельное оформление лексем без дефиса в силу большей экономичности и выразительности.

Данная словообразовательная модель оказалась достаточно продуктивной. Каждый новый всплеск протестной активности в Украине стал обозначаться деонимом-композитом, который объяснял аудитории, с кем из политиков связана эта активность.

Так, в 2019 году в политическом медиадискурсе появился неологизм Штайнмайер-майдан, то есть протест, связанный с выполнением предложений немецкого политика Ф. В. Штайнмайера относительно изменений украинского законодательства: Если «Штайнмайер-майдан» победит: Что ждет Украину (Голос.юа, 15. 10. 2019).

В том же году протесты сторонников Петра Порошенко против политики Владимира Зеленского получили в медиа название Порох-майдан: Порох-майдан удивил. Но не тем, что удался, а скорее наоборот (Страна.юа, 8. 12. 2019).

Ещё одной продуктивной группой деонимов-композитов являются слова, созданные по модели «оним + робот», имеющие значение «горячий сторонник определенного политика» с отрицательной коннотацией. Эти слова возникли под влиянием медиадискурса США, в котором в 2010 году появилась и стала популярной лексема obamabot. Неологизм зафиксирован в электронном словаре Университета Райса, где толкуется следующим образом: «обамабот - защитник политики президента Обамы. Используется как оскорбление сторонников Обамы. Термин также намекает на роботов, которые завладели миром и разрушили его» ${ }^{14}$.

Неологизм быстро обрёл популярность, и сейчас эта словообразовательная модель употребляется по отношению к сторонникам других президентов США,

14 THE RICE UNIVERSITY NEOLOGISMS DATABASE < https://neologisms.rice.edu/index.php?a= term $\& \mathrm{~d}=1 \& \mathrm{t}=8935>$. [online]. [cit. 14. 1. 2020]. 
например, Дональда Трампа: Meet Trumpbot, the bot that tries to talk like Trump (Washington Post, 16. 1. 2018).

В русскоязычном политическом медиадискурсе подобные композиты широко используются для обозначения сторонников украинских политиков. Так, во время украинской президентской кампании 2019 года распространилась модификация, возникшая на базе фамилии Петра Порошенко: «Порохоботы» и «зеленые»: зачем Россия настраивает украинцев друг против друга, создавая в Украине два лагеря (5 канал, 12. 11. 2019); Порохоботы и наиионалисты атакуют Зе за формулу по Донбассу. Чем это грозит? (Страна.юа, 2. 10. 2019).

Сторонников оппонента Петра Порошенко Владимира Зеленского называют по-разному - или зелеботами: Зелеботы: кто это такие, почему их называют «девочками» и «мелкотравчатыми» (Ua.portal, 27. 4. 2019), или зеботами: ЗЕботы. Как действует сетевая армия Зеленского и чем она отличается от порохоботов (Страна.юа, 22. 8. 2019).

Во втором случае, по нашему мнению, «срабатывает» медийное клише называть всё, что касается президента Владимира Зеленского, словами с формантом зе- (например, зе-команда, зе-новости).

Лексемы с этим формантом в современном политическом дискурсе очень популярны, их используют и сторонники президента, и его оппоненты: Нормандская ЗЕ-команда. Зачем Зеленский взял в Париж Авакова и Баканова (Вести.юа, 10. 12. 2019); Зе-команда в действии: стало известно, кто из «слуг народа» пропустил больше всего голосований (5 канал, 30. 9. 2019).

Анализ словоупотреблений в медиадискурсе свидетельствует об устойчивой тенденции, суть которой заключается в том, чтобы уточняющие форманты в композите ставились перед основным словом, как это обычно делается в английском языке. Например: Тягнибок на анти-Зе митинге призвал к «перепаспортизации» жителей Донбасса (Страна.иа, 8. 12. 2019).

Лексема-композит анти-Земитинг с семантикой «митинг, направленный против политики Владимира Зеленского» является типичной калькой американских сложных образований anti-Trump protest или anti-Trump delusions. Например: The exhaustion of Democrats' anti-Trump delusions (The Hill, 20. 8. 2019); Anti-Trump protest planned in London during December visit (Reuters, 21. 1. 2019).

Таким образом, исследование русскоязычного политического медиадискурса свидетельствует о продуктивности деривационных моделей деонимов, возникших под влиянием английского языка, а именно: деонимов с формантом -инг и разнообразных композитов.

Активное возникновение и распространение в языке СМИ на постсоветском пространстве новых лексических единиц с ономастическим компонентом является свидетельством важных изменений в общественном сознании. 
Политика, с одной стороны, персонифицируется, власть из безликого монолита превращается в сообщество конкретных личностей, каждая из которых наделена индивидуальными чертами, с другой стороны - она теряет ореол чего-то высокого в глазах рядового обывателя. И немаловажную роль в этом процессе играет пласт деонимической лексики. Замена словосочетания «митинг сторонников Владимира Путина» экспрессивной лексемой путинг и называние протестных акций, организованных Михаилом Саакашвили, ёмким словом Михоайдан говорят не только о влиянии словообразовательных моделей английского языка на русский или о тенденции к экономии языковых средств. Лингвистика в данном случае отражает сдвиги в общественном сознании. Языковая игра, стремление к выразительности и эмотивности публицистического текста, проявляющиеся в создании новых лексем-деонимов с ономастическим компонентом, могут рассматриваться в качестве маркеров процесса социальной трансформации на постсоветском пространстве.

\section{Литература:}

BELOV, V.: Nekotoryje leksičeskije processy $v$ rossijskom političeskom diskurse (na materiale rossijskich Internet-gazet). Zeitschrift für Slavische Philologie, 2016, vol. 72, iss. 2, pp. 383-411. ISSN oo44-3492.

CONEVA, L. M.: Osobennosti jazykovoj igry v sovremennych SMI. In: MARKOVA, Je. M., DOHNAL, J. (eds): Osnovnyje tendencii razvitija russkogo i drugich slavjanskich jazykov v sovremennom mire. Brno: Tribun EU, 2014, s. 306-311. ISBN 978-80-263-0595-8.

D'JAKOV, A. I., SKVORECKAJA, JE. V.: Suffiks -ing zavojevyvajet svoi pozicii v russkom slovoobrazovanii. Sibirskij filologičeskij žurnal, 2013, nr 4, s. 180-186. ISSN 1813-7083.

GLADČENKOVA, Je. A.: Izmenenije vnešnej $i$ vnutrennej formy precedentnych antroponimov $v$ žargonnoj frazeologii. Izvestija Južnogo federal'nogo universiteta. Filologičeskije nauki, 2011, nr 3, s. 156-162. ISSN 1995-0640.

GORHAM, M.S., LUNDE, I., PAULSEN, M.: Digital Russia: The Language, Culture and Politics of New Media Communication. London: Routledge, 2014, 312 p. ISBN 0415707048.

GRIGOR'JEV, V.P.: Svetloje buduščeje «ingovych form»v russkom poètičeskom jazyke. 2005. <http://www.vavilon.ru/textonly/issue13/grigoriev.html>. [online]. [cit. 1. 12. 2019]. 
JAKUŠEVA, A. V.: K semantike političeskogo teksta: antroponimy v funkcional'noj srede setevych sredstv massovoj informacii. Gumanitarnyje, social'no-èkonomičeskije i obščestvennyje nauki, 2014, nr 6, s. 1-6. ISSN 2220-2404.

KATERMINA, V. V.: Ocenočnyje nominacii politikov (na materiale russkoj i anglijskoj substandartnoj leksiki). Političeskaja lingvistika, 2015, nr 3 (53), s. 26-31. ISSN 1999-2629 .

KONIECZNA, E.: Polish onomastic derivatives in the contemporary political discourse in the light of internationalization of Slavic languages. Zeitschrift für Slawistik, 2011, vol. 56, iss. 1, pp. 97-107. ISSN 0044-3506.

LUNDE, I.: Hashtag Poetics: Political humour on Russian Twitter. Zeitschrift für Slawistik, 2016, vol. 61, iss. 1, Special Issue: Contemporary Eastern European political discourse, pp. 102-118. ISSN 0044-3506.

MARKEVIČ, V. I.: Nacional'no-kul'turnaja specifika frazeologizmov s komponentom-antroponimom v russkom, belorusskom i nemeckom jazykach. Filologičeskije nauki. Voprosy teorii i praktiki, 2014, nr 7 (37), II, s. 136-139. ISSN 1997-2911.

SANNIKOV, V.Z.: Russkij jazyk v zerkale jazykovoj igry. Moskva: Jazyki slavjanskoj kul'tury, 2002, 552 s. ISBN 5-94457-037-7.

THE RICE UNIVERSITY NEOLOGISMS DATABASE < https://neologisms.rice.edu/ index.php? $\mathrm{a}=$ term $\& \mathrm{~d}=1 \& \mathrm{t}=8935^{>}$. [online]. [cit. 14. 1. 2020].

\section{Источники экземплификации:}

5 канал. URL: https://www.5.ua/

Вести FM. URL: https://radiovesti.ru/main/

Вести.юа. URL: https://vesti.ua/

Голос.юа. URL: https://golos.ua/

Гордон.ua. URL: https://gordonua.com/

Журналистская Правда. URL: https://jpgazeta.ru/

ИA REGNUM. URL: https://regnum.ru/

Империя. URL: http://www.imperiyanews.ru/

Новый день. URL: https://newdaynews.ru/

Радио Свобода. URL: https://www.svoboda.org/

Ридус. URL: https://www.ridus.ru/

Свободная пресса. URL: https://svpressa.ru/

Страна.ua. URL: https://strana.ua/

Проза.py. URL: https://proza.ru/

Украинская правда. URL: https://www.pravda.com.ua/rus/

Фонтанка. URL: https://www.fontanka.ru/ 
CBSMEDIA. URL: https://cbsmedia.ru/

The Hill. URL: https://thehill.com/

Reuters. URL: https://www.reuters.com/

Ua.portal. URL: https://www.uaportal.com/

Washington Post. URL: https://www.washingtonpost.com/

\author{
About the author \\ Elena Tomášková \\ Institute of Technology and Business in České Budějovice, Faculty of Corporate Strategy, \\ Centre of Language Services, České Budějovice, Czech Republic \\ tomaskova@mail.vstecb.cz
}


